\title{
Author Correction: A shape-shifting redox foldase contributes to Proteus mirabilis copper resistance
}

\author{
Emily J. Furlong ${ }^{1}$, Alvin W. Lo 2,3, Fabian Kurth ${ }^{1,6}$, Lakshmanane Premkumar,2,7, Makrina Totsika ${ }^{2,3,8}$, \\ Maud E.S. Achard ${ }^{2,3,9}$, Maria A. Halili', Begoña Heras ${ }^{4}$, Andrew E. Whitten ${ }^{1,10}$, Hassanul G. Choudhury ${ }^{1,11}$, \\ Mark A. Schembri ${ }^{2,3}$ \& Jennifer L. Martin ${ }^{1,5}$
}

Correction to: Nature Communications; https://doi.org/10.1038/ncomms16065; published online 19 July 2017

This Article contains errors in Fig. 1, Table 1 and the Methods section. In panel c, the labels for PmScsC and EcDsbC in the upper two curves are interchanged. In Table 1 and the Methods section entitled 'Extended structure', the space group of the extended PmScsC structure is incorrectly referred to as $\mathrm{H}_{3}$ and should read $\mathrm{H} 32$. Correct versions of Fig. 1 and Table 1 are presented below; the errors have not been corrected in the Article.

Published online: 01 March 2019

Open Access This article is licensed under a Creative Commons Attribution 4.0 International License, which permits use, sharing, adaptation, distribution and reproduction in any medium or format, as long as you give appropriate credit to the original author(s) and the source, provide a link to the Creative Commons license, and indicate if changes were made. The images or other third party material in this article are included in the article's Creative Commons license, unless indicated otherwise in a credit line to the material. If material is not included in the article's Creative Commons license and your intended use is not permitted by statutory regulation or exceeds the permitted use, you will need to obtain permission directly from the copyright holder. To view a copy of this license, visit http://creativecommons.org/licenses/by/4.0/.

(C) The Author(s) 2019

\footnotetext{
${ }^{1}$ Institute for Molecular Bioscience, University of Queensland, St. Lucia, QLD 4072, Australia. ${ }^{2}$ School of Chemistry and Molecular Biosciences, University of Queensland, St. Lucia, QLD 4072, Australia. ${ }^{3}$ Australian Infectious Diseases Research Centre, University of Queensland, St. Lucia, QLD 4072, Australia. ${ }^{4}$ La Trobe Institute for Molecular Science, La Trobe University, Bundoora, VIC 3068, Australia. ${ }^{5}$ Griffith Institute for Drug Discovery, Griffith University, Nathan, QLD 4111, Australia. ${ }^{6}$ Present address: Bristol-Myers Squibb, Arnulfstraße 29, 80636 Munich, Germany. ${ }^{7}$ Present address: Department of Microbiology and Immunology, School of Medicine, University of North Carolina, Chapel Hill, NC 27514, USA. ${ }^{8}$ Present address: Institute of Health and Biomedical Innovation, School of Biomedical Sciences, Queensland University of Technology, Kelvin Grove, QLD 4059, Australia. ${ }^{9}$ Present address: School of Human Movement and Nutrition Sciences, University of Queensland, St. Lucia, QLD 4072, Australia. ${ }^{10}$ Present address: Australian Centre for Neutron Scattering, Australian Nuclear Science and Technology Organization, Lucas Heights, New South Wales 2234, Australia. ${ }^{11}$ Present address: Cello Health Consulting, Farnham Surrey GU9 7DN, UK. Correspondence and requests for materials should be addressed to A.E.W. (email: awh@ansto.gov.au) or to M.A.S. (email: m.schembri@uq.edu.au) or to J.L.M. (email: jlm@griffith.edu.au)
} 
a

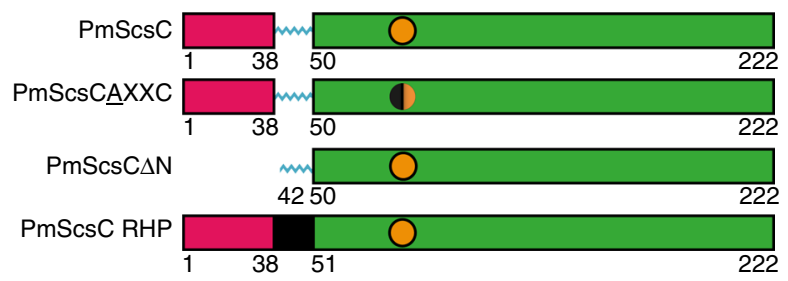

\section{b}

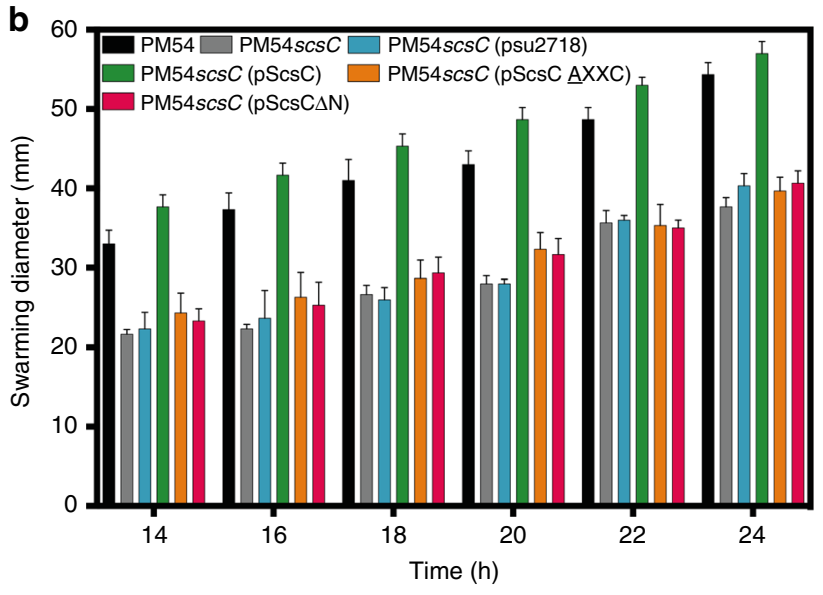

C

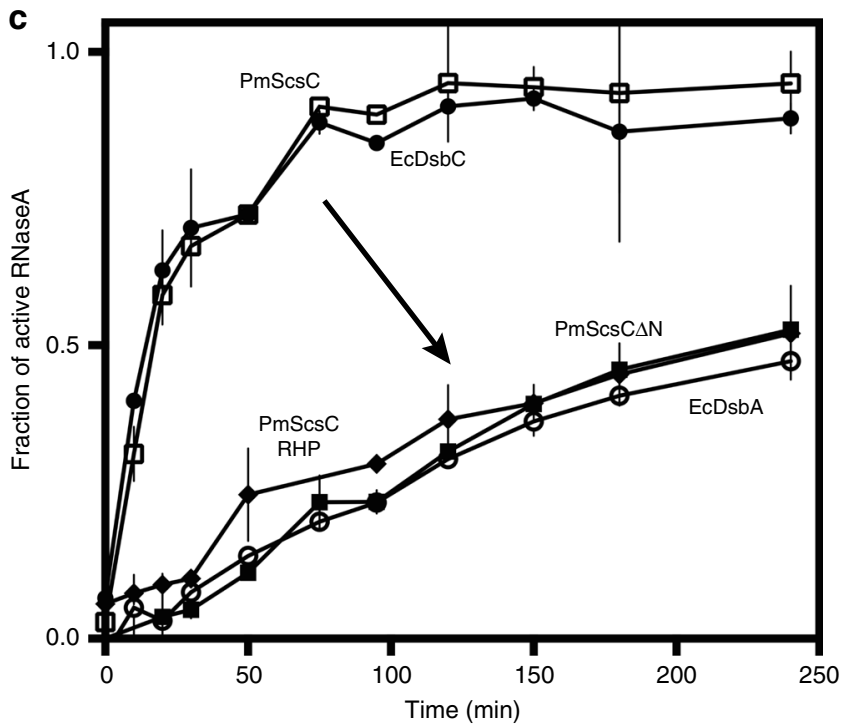

Table 1 PmScsC crystal structure statistics

\begin{tabular}{|c|c|c|c|}
\hline & $\begin{array}{l}\text { Compact } \\
\text { (4XVW) }\end{array}$ & $\begin{array}{l}\text { Transitional } \\
\text { (5IDR) }\end{array}$ & $\begin{array}{l}\text { Extended } \\
\text { (5ID4) }\end{array}$ \\
\hline \multicolumn{4}{|l|}{ Data collection } \\
\hline Space group & $\mathrm{P} 2_{1}$ & 14 & $\mathrm{H} 32$ \\
\hline \multicolumn{4}{|l|}{ Cell dimensions } \\
\hline$a, b, c(\AA)$ & $\begin{array}{l}\text { 137.5, 163.9, } \\
181.9\end{array}$ & $\begin{array}{l}\text { 193.1, 193.1, } \\
105.8\end{array}$ & $\begin{array}{l}86.7,86.7 \\
330.9\end{array}$ \\
\hline$\alpha, \beta, \gamma(\stackrel{\circ}{)})$ & $90,90,90$ & $90,90,90$ & $90,90,120$ \\
\hline Resolution $(\AA)$ & $\begin{array}{l}91.15-2.60 \\
(2.74-2.60)\end{array}$ & $\begin{array}{l}136.51-2.56 \\
(2.57-2.56)\end{array}$ & $\begin{array}{l}110.29-2.92 \\
(2.93-2.92)\end{array}$ \\
\hline$R_{\text {merge }}$ & $0.072(0.617)$ & $0.083(0.741)$ & $0.059(0.625)$ \\
\hline$I / \sigma \mid$ & $11.0(2.0)$ & $14.9(2.2)$ & $14.2(2.8)$ \\
\hline $\begin{array}{l}\text { Completeness } \\
(\%)\end{array}$ & $98.6(95.4)$ & $99.4(100.0)$ & $99.2(100.0)$ \\
\hline Redundancy & $3.8(3.7)$ & $4.1(4.1)$ & $4.1(4.2)$ \\
\hline \multicolumn{4}{|l|}{ Refinement } \\
\hline Resolution $(\AA)$ & $91.15-2.60$ & $42.82-2.56$ & $40.36-2.92$ \\
\hline No. of reflections & 243,409 & 62,069 & 10,652 \\
\hline$R_{\text {work }} / R_{\text {free }}(\%)$ & $24.8 / 28.2$ & $17.1 / 22.2$ & $25.1 / 26.3$ \\
\hline \multicolumn{4}{|l|}{ No. of atoms } \\
\hline Protein & 40,850 & 10,262 & 1720 \\
\hline Ligand/ion & NA & NA & NA \\
\hline Water & 281 & 82 & 0 \\
\hline \multicolumn{4}{|l|}{$B$ factors $\left(\AA^{2}\right)$} \\
\hline Protein & 59.7 & 50.6 & 122.2 \\
\hline Ligand/ion & NA & NA & NA \\
\hline Water & 41.5 & 43.0 & NA \\
\hline \multicolumn{4}{|l|}{ RMS deviations } \\
\hline Bond length $(\AA)$ & 0.006 & 0.008 & 0.010 \\
\hline Bond angles $(\stackrel{0}{)}$ & 1.21 & 1.05 & 1.17 \\
\hline
\end{tabular}

Fig. 1 